\title{
Transformation of the Structure \\ of the Sintered Aluminum Bronze with the Free Forging
}

\author{
Alexey V. Gurskikh* \\ JSC "POLEMA", Research Laboratory \\ 3 Przhevalskogo Str., Tula, 300016, Russia
}

Received 19.11.2017, received in revised form 21.12.2017, accepted 07.01.2018

Sintered materials exhibit some reduction in mechanical properties due to residual porosity. To eliminate the defects that arise during sintering, a pre-compacting operation combined with shaping is applied. Because the pressing force is limited, it is possible to increase the density of the compacted sample only by decreasing its area, increasing the load on the tool, or by heating the workpiece to a temperature markedly decreasing the strength of the pressed material. It is possible to oxidize the material in open pores. After the collapse of the pores, further deformation of the material is not possible, and the values of the tested material may not be sufficient for a substantial study of the structure in the entire volume of the sintered material.

When the samples are free of sediment, the amount of superimposed deformation is limited only by the power of the press tool, because during the sedimentation of the samples, the area of their cross sections increases, and the deformation hardening of the material. The material flow is carried out by shifting along the planes of the maximum shearing stresses. In the course of the work, the influence of temperature on the behavior of single-phase cu-15 at. \% al and two-phase cu-24 at. $\%$ al compositions on the behavior of a special bronze was studied. It was established that the sediment of samples from sintered alloys without destruction can reach $30 \%$. The increase in the pressing temperature leads to a significant decrease in the working pressure, but a noticeable compaction of the material is observed only at a temperature above $500^{\circ} \mathrm{C}$, when the deformation begins to be distributed uniformly over the volume of the samples.

Keywords: hot pressing, intensive plastic deformation, aluminium bronze, sintered alloys.

Citation: Gurskikh A.V. Transformation of the structure of the sintered aluminum bronze with the free forging, J. Sib. Fed. Univ. Eng. technol., 2018, 11(2), 181-189. DOI: 10.17516/1999-494X-0021.

(C) Siberian Federal University. All rights reserved

* Corresponding author E-mail address: avg@polema.net 


\title{
Преобразование структуры
}

\section{спеченной алюминиевой бронзы}

при свободной ковке

\author{
А.В. Гурских \\ АО «ПОЛЕМА», исследовательская лаборатория \\ Россия, 300016, Тула, ул. Пржевальского, 3
}

Спеченные материаль демонстрируют некоторое снижение механических свойств из-за остаточной пористости. Для устранения дефектов, возникаюших при спекании, применяют операцию доуплотнения, совмещенную с формообразованием. В силу того, что усилия прессования ограничены, плотность прессуемого образца повышается только за счет уменьшения его площади, с возрастанием нагрузки на инструмент, или за счет нагрева заготовки до температуры, заметно снижающей прочность прессуемого материала. При этом возможно окисление материала в открытых порах. После схлопывания пор дальнейшая деформация материала невозможна, а величины испытанной может оказаться недостаточной для существенной проработки структуры во всем объеме спеченного материала.

При свободной осадке образцов величина наложенной деформации ограничивается только мощностью прессового инструмента, поскольку во время осадки образиов происходит увеличение площзади их сечения, а также деформационное упрочнение материала. Течение материала осуществляется сдвигом вдоль плоскостей максимальных сдвигаюших напряжений. В ходе работы было исследовано влияние температуры на поведение при сжатии спеченной бронзы однофазного Cu-15 ат.\% Al и двухфазного Cu-24 ат.\% Al составов. Установлено, что осадка образиов из спеченных сплавов без разрушения может достигать 30 \%. Повышение температуры прессования приводит к значительному снижению рабочего давления, однако заметное уплотнение материала наблюдается только при температуре выше $500{ }^{\circ} \mathrm{C}$, когда деформация начинает распределяться по объему образиов относительно однородно.

Ключевые слова: горячее прессование, интенсивная пластическая деформаџия, алюминиевая бронза, спеченные сплавы.

\section{Введение}

Для спеченных материалов характерно наличие остаточной пористости и неоднородное распределение легирующих компонентов [1], что обусловливает снижение их механических свойств. Для устранения указанных дефектов спеченные изделия подвергают доуплотнению, совмещая его с формообразованием. Во время такой обработки осуществляется модификация исходной структуры, степень которой зависит не только от величины наложенной деформации, но и от однородности ее распределения по объему образца, зависящей во многом от применяемой механической схемы деформации.

Например, при доуплотнении спеченных образцов в закрытых штампах изменение их поперечного сечения ограничено стенками пресс-формы и процесс протекает при высоком гидростатическом давлении. Полностью устранить поры в массивных образцах таким методом нельзя, поскольку по мере уплотнения материала для заковки оставшихся пор требуется все большее гидростатическое давление [2]: $\eta=\exp -(\sqrt{3} / c)(p / \tau)$. Здесь $\eta-$ текущая пористость образца, $p$ - гидростатическое давление на поверхности пор, $\tau$ - максимальное напряжение сдвига материала, а $c$ - коэффициент формы пор, равный 0.33 для цилиндрических и 0.25 для сфериче- 
ских пор. Ввиду ограниченности усилия прессования повысить плотность прессуемого образца можно только за счет уменьшения его площади (при этом возрастет нагрузка на инструмент) или за счет нагрева заготовки до температуры, заметно снижающей прочность прессуемого материала. При этом нужны специальные меры по предотвращению окисления материала в открытых порах. После схлопывания пор дальнейшая деформация материала невозможна, а величины испытанной может оказаться недостаточно для существенной проработки структуры во всем объеме спеченного материала.

При свободной осадке образцов величина наложенной деформации ограничивается только мощностью прессового инструмента, поскольку во время осадки образцов происходит увеличение площади их сечения, а также деформационное упрочнение материала. Течение материала осуществляется сдвигом вдоль плоскостей максимальных сдвигающих напряжений. Если обрабатываемый материал пористый, то указанные плоскости проходят, в том числе, и через поры. Половинки пор смещаются, площадь их поверхности увеличивается, и берега пор начинают сближаться под действием гидростатического давления, величина которого определяется напряжением течения деформируемого материала. По мере сплющивания и вытягивания поры постепенно превращаются в трещины Гриффитса, устойчивость которых определяется уровнем растягивающих напряжений на концах трещин. Растрескивание материала вследствие самопроизвольного роста указанных дефектов определяет величину допустимой деформации спеченных образцов. Поскольку положение плоскостей максимальных сдвигающих напряжений при монотонных видах деформирования, к которым относится и свободная осадка, не меняется, поры могут достаточно быстро принять опасные форму и размер, особенно если при этом пластическое течение материала склонно к локализации.

Целью настоящей работы является изучение влияния температуры прессования на предельную величину деформации, не вызывающую растрескивание образцов в процессе их одноосной осадки, а также особенности эволюции поровой и зеренной структуры спеченных бронзовых одно- и двухфазных сплавов при такой обработке.

\section{Материалы и методика эксперимента}

В качестве материала для исследований использовались спеченные при $950{ }^{\circ} \mathrm{C}$ прессовки цилиндрической формы, полученные из смесей порошков меди марки ПМС-1 и алюминия марки ПА-4, взятых в соотношении, соответствующем $\alpha-$-твердому раствору алюминия в меди (15 ат.\% Al - сплав 1), а также выходящем за область твердого раствора (24 ат.\% $\mathrm{Al}$ - сплав 2). Пористость спеченных образцов составляла 20-25 \%. Одноосное сжатие образцов для определения предельно допустимых значений деформации осуществляли на установке МC-500 при комнатной температуре или после предварительного подогрева пресс-формы вместе с образцами в печи СНОЛ до $250 \div 600{ }^{\circ} \mathrm{C}$.

Шлифы для металлографических исследований микроструктуры образцов готовили по обычной методике. При анализе структуры особое внимание уделяли характеру эволюции пор, изменению их размеров и формы. Для описания формы пор использовали параметр $\mathrm{K}=\mathrm{d}_{\min } /$ $\mathrm{d}_{\max }$ как соотношение их минимального диаметра к максимальному [3]. На основе полученных статистических данных строили гистограмму, позволяющую выявить удельную долю пор определенной формы в исследуемом материале.

$$
-183-
$$


Дополнительно измеряли микротвердость деформированных образцов с помощью прибора ПМТ-3 при нагрузке на индентор 20 г и выдержке 10 с.

\section{Результаты и их обсуждение}

В спеченном состоянии сплав 1 представляет собой однофазный материал на основе $\alpha-$-вердого раствора алюминия в меди с выраженной дендритной структурой, средний размер зерен которой равен 30-60 мкм (рис. 1a). Другим элементом структуры спеченной бронзы были поры с преобладанием узких вытянутых пор, расположенных в междендритных промежутках и крупных округлых пор со средним диаметром 30-50 мкм, образовавшихся на месте растворившихся частиц алюминия в меди. Такая структура типична для спеченных сплавов с односторонней растворимостью легирующего элемента [4]. Микротвердость спеченного сплава в среднем составляла $(700 \pm 35)$ МПа.

Осноа структуры сплава 2 после спекания - чередующиеся со средней толщиной 2-3 мкм

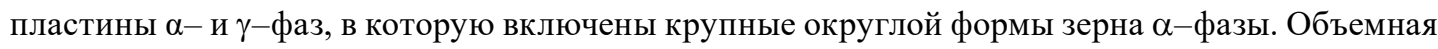
доля $\gamma$-фазы равнялась примерно $42 \%$, что согласуется с диаграммой фазового равновесия системы $\mathrm{Cu}-\mathrm{Al}$ [5]. Микротвердость эвтектоидных областей составляла (2173 \pm 50$)$ МПа, а заключенных в них зерен твердого раствора $\alpha-$ фазы - (1175 \pm 20$)$ МПа.

Поры в спеченных сплавах 1 и 2 имеют бимодальное распределение по форме и размерам. Средний диаметр крупных округлых пор, образовавшихся на месте растворившихся частиц
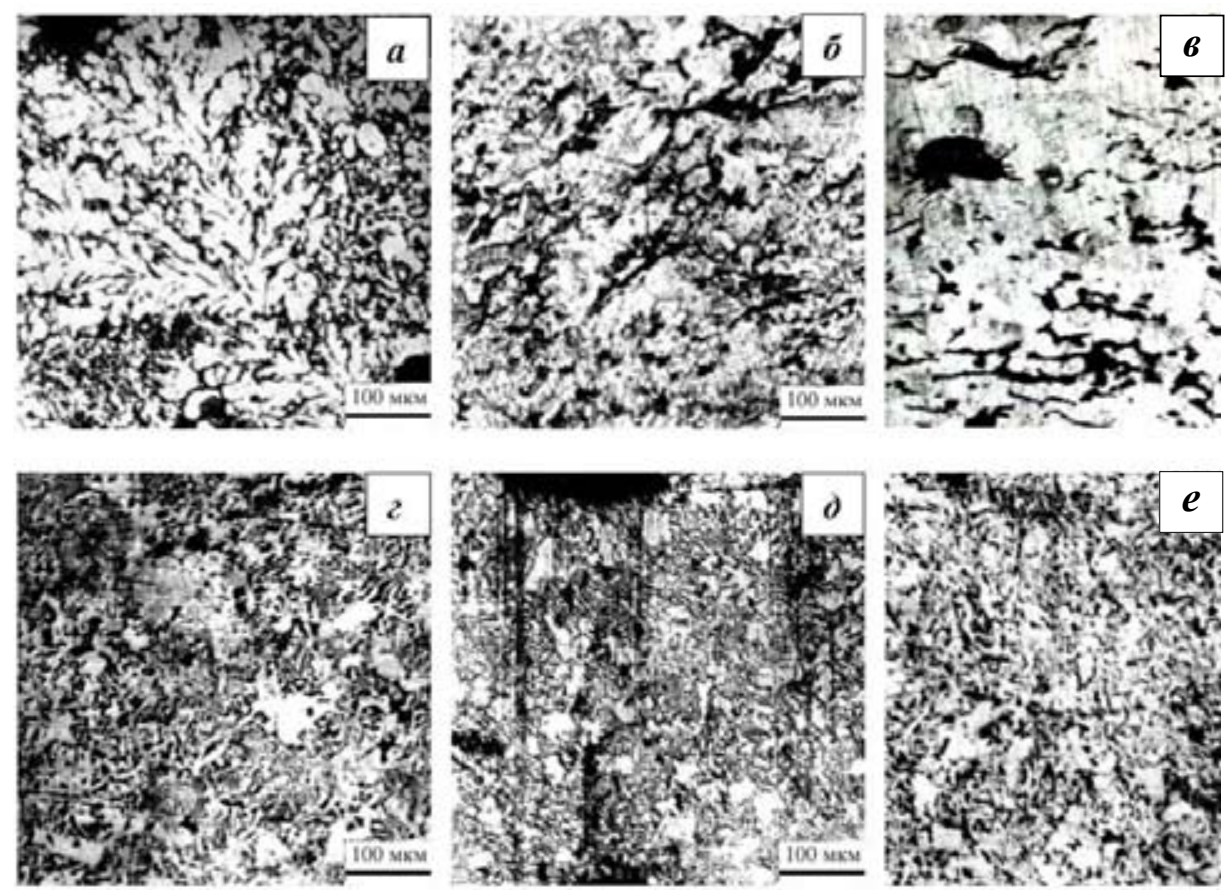

Рис. 1. Микроструктура порошковых сплавов: сплав 1 в исходном состоянии (a); после деформирования при 20 (б) и при $600{ }^{\circ} \mathrm{C}$ (в); сплав 2 в исходном состоянии (г); после деформирования при 20 (д) и при $600^{\circ} \mathrm{C}(\mathrm{e})$

Fig.1. Microstructure of powder alloys: alloy 1 in the initial state (a); after deformation at 20 (б) and at $600{ }^{\circ} \mathrm{C}$ (в); alloy 2 in the initial state (г); after deformation at 20 (д) and at $600{ }^{\circ} \mathrm{C}(\mathrm{e})$ 
алюминия в меди [6], в сплаве 1 составил 30-50 мкм, а в двухфазном сплаве 2-50-60 мкм. Мелкие и вытянутые поры располагались либо в междендритном пространстве в сплаве 1 , либо в двухфазных областях в случае сплава 2 (рис. $1 a$ и г) и при определении $K$ не учитывались.

Суммарная величина осадки образцов из сплава 1 равнялась примерно $30 \%$. В результате их плотность заметно повышается, однако характер уплотнения и особенности эволюции поровой структуры материала существенно зависели от температуры прессования. О характере ее протекания и распределении деформации по объему образца можно судить по изменению формы кривой распределения параметра $\mathrm{K}$, которая в спеченном материале есть кривая с выраженным максимумом вблизи больших его значений. Например, если при осадке образца деформация распределяется по объему равномерно, то и максимум будет смещаться в сторону меньших К, но форма кривой распределения останется примерно той же, что и до прессования. При неоднородном течении материала максимум будет размываться и снижаться за счет появления малых значений К.

Так, на рис. $2 a$ видно, что усадка образцов при температурах 20 и $370{ }^{\circ} \mathrm{C}$ протекает однородно не по всему объему образцов, особенно в первом случае, поскольку по окончании прессования остается значительная часть крупных округлых исходных пор. Напротив, при осадке при $600{ }^{\circ} \mathrm{C}$ таких пор практически не осталось, кривая (4) распределения параметра $\mathrm{K}$ имеет острый максимум в районе сильно сплющенных пор. На рис. 1 видно, что такие поры имеют не только сплющенную форму, как после осадки при более низкой температуре (рис. 1б), но и мелкий размер, поскольку многие из них оказались пережатыми, а стенки пор в местах пережима срослись (рис. 16). Исходная дендритная структура сплава 1 в процессе сжатия была разрушена (рис. 1) независимо от температуры прессования.

Изменения структуры пор при сжатии двухфазного сплава 2 имеют примерно такой же характер, как и в предыдущем случае (рис. 1 и 2). После осадки на 30 \% в материале остается заметная доля (около 10 \%) исходных округлых пор. При этом поры с $\mathrm{K}<0.2$ появляются только при высокотемпературной осадке. То есть при осадке образцов распределение деформации по
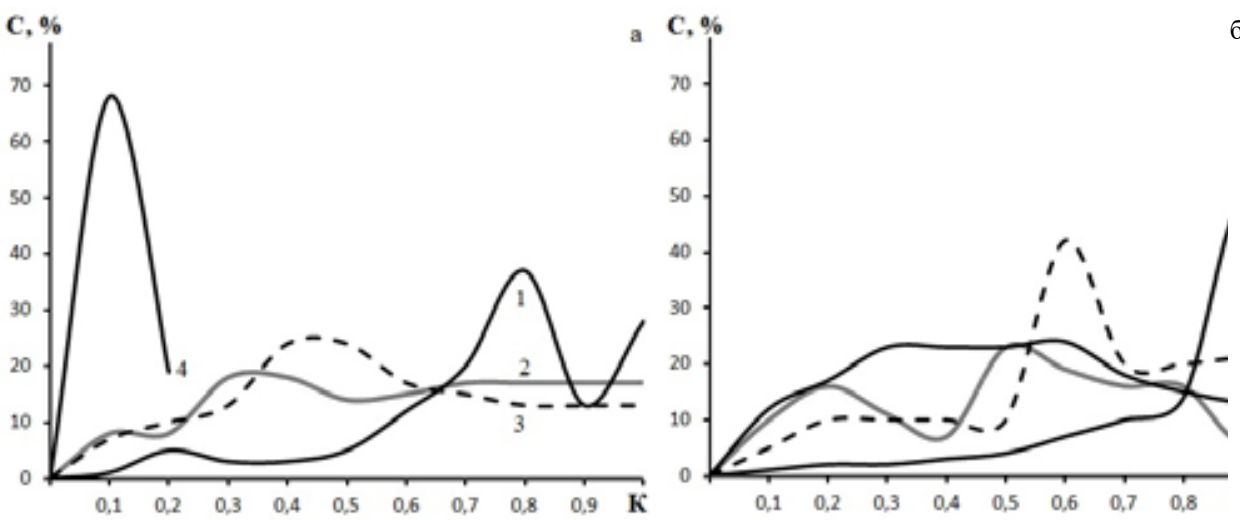

Рис. 2. Распределения пор по конфигурации $\left(\mathrm{K}=\mathrm{d}_{\min } / \mathrm{d}_{\max }\right)$ в сплаве 1(а) и сплаве $2(б): 1-$ в исходном состоянии; 2-4 - после осадки при 20,370 и $600{ }^{\circ} \mathrm{C}$ соответственно

Fig. 2. Pore distributions by configuration $\left(K=d_{\min } / d_{\max }\right)$ in alloy 1 (a) and alloy 2 (б): $1-$ in the initial state; 2-4 - after deformation at 20,370 and $600{ }^{\circ} \mathrm{C}$, respectively 
их объему остается относительно неоднородным, поэтому пик кривой К не только смещается к большим значениям параметра, но и снижается. Кривая распределения К становится более пологой.

Из проведенного анализа кривых распределения К следует, что материал в окрестностях пор упрочнен сильнее, чем на большом расстоянии от них. Происходит это по той причине, что вокруг исходных частиц алюминия быстро образуется интерметаллический слой меди, насыщенный атомами алюминия, который тормозит растекание эвтектической жидкости по объему прессовки. За время существования интерметаллидного барьерного слоя прилегающие к нему слои меди успевают сильнее насытиться атомами алюминия, чем отстоящие более далеко медные частицы, к которым алюминий подводится только после расплавления интерметаллидного слоя. Особенно заметен этот эффект в случае сплава 1. Однако при нагреве прессовки до $600{ }^{\circ} \mathrm{C}$ механическая прочность $\alpha$-фазы сильно снижается, эффект от твердорастворного упрочнения нивелируется и все поры сильно сжимаются (рис. $2 a$, кривая 4).

В случае сплава 2 поры окружены слоем двухфазного материала, который менее подвержен высокотемпературному разупрочнению. Поэтому форма пор при ковке образцов подвергается меньшему изменению, доля их с малыми значениями $\mathrm{K}$ незначительна. Пластическое течение по мере деформационного упрочнения материала начинает локализоваться в более мягких областях. Это видно по структуре сплава на рис. 1, где целые области, не охваченные пластическим течением, сохраняют свою исходную структуру с чередующимися пластинами $\alpha$ - и $\gamma$-фаз. Только нагрев сплава 2 до $600{ }^{\circ} \mathrm{C}$, когда выделения второй фазы трансформируются из твердой $\gamma$-фазы в более пластичную $\beta$-фазу [4], приводит к вовлечению в пластическое течение областей вокруг пор, что незамедлительно сказывается на появлении последних с малым значением К (рис. 2, кривая 4), и полному разрушению пластинчатых выделений на мелкие дисперсные частицы (рис. $1 e$ ).

О существенном разупрочнении сплава 2 из-за распада $\gamma$-фазы при $600{ }^{\circ} \mathrm{C}$ свидетельствует и соответствующая кривая течения 5 на рис. 3. Прочность сплава при деформации образцов почти до 25 \% практически не растет, только после деформационной проработки всего материала начинает медленно увеличиваться.
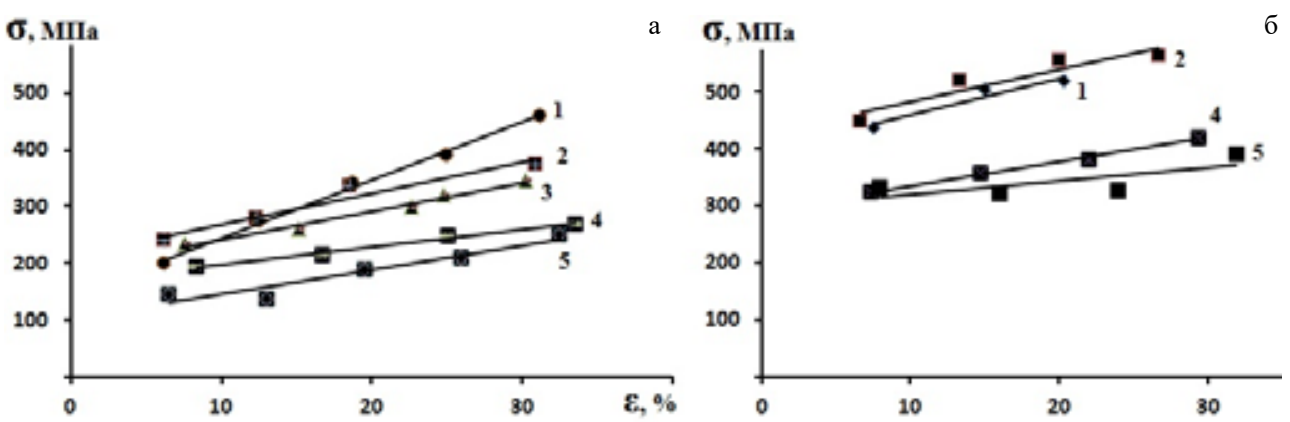

Рис. 3. Кривые «напряжения - деформация» для составов 1 (a) и 2 (б) при температуре деформирования $20(1), 250(2), 370(3), 500$ (4) и $600{ }^{\circ} \mathrm{C}(5)$

Fig. 3. Curves «stress-strain» for alloys 1 (a) and 2 (b) at a deformation temperature of 20 (1), 250 (2), 370 (3), 500 (4) and $600{ }^{\circ} \mathrm{C}(5)$ 
В случае более низкой температуры осадки, когда частицы второй фазы сохраняются в своей твердой и хрупкой $\gamma$-модификации, их влияние на скорость упрочнения материала при прессовании незначительное. Кривые течения 1-4 на рис. 3 у обоих сплавов имеют практически равный наклон. Видимо, при развитии деформации вдоль линий максимального сдвигового напряжения пластинчатые выделения хрупкой фазы легко разрушаются и не оказывают значительного сопротивления. При низких температурах прессования таких разрушений множество, микротрещины становятся источниками критических разрушающих напряжений и, сливаясь, быстро подрастают до критических размеров. Поэтому предельная степень осадки образцов двухфазного сплава 2 оказывается ограниченной, ее величина не дотягивает до 30 \% (рис. 36 , кривая 1 и 2).

Напряжение течения образцов сплава 2 композиционного состава определяется объемной долей твердой и мягкой фаз, т.е. по закону механической смеси. Однако с началом пластического течения включения $\gamma$-фазы разрушаются и влияния на темпы деформационного упрочнения материала практически не оказывают. Деформационное упрочнение спеченных бронз обеспечивается упрочнением пластичной $\alpha$-фазы. На это указывает тот факт, что наклон кривых течения сплава 2 и сплава 1 фактически совпадают (рис. $3 a$ и б), т.е., при осадке бронзовых образцов действует один и тот же механизм деформационного упрочнения материала независимо от наличия в нем частиц хрупкой $\gamma$-фазы.

В то же время наклон деформационной кривой сплава 1 при холодном прессовании несколько выше, чем у остальных кривых (рис. $3 a$, график 1), т.е., упрочнение материала происходило более быстрыми темпами. Специальных исследований по объяснению этому факту не проводилось, но можно предположить, что по причине неравномерного распределения алюминия по объему спеченного материала в некоторых его областях сопротивление движению дислокаций выше, например, из-за образования тормозящих скоплений по типу облаков Сузуки. С повышением температуры прессования и увеличением подвижности атомов алюминия дислокации от них отрываются более легко или таких облаков вовсе не образуется из-за быстрого выравнивания концентрации элементов.

Как следует из рис. 3, поровая структура спеченных сплавов также оказывает незначительное влияние на скорость упрочнения, хотя, согласно данным табл. 1, ее количественные характеристики существенно отличаются в зависимости от состава спеченной бронзы и температуры ее обработки. В то же время, как видно из данных таблицы, величина конечной пористости деформированных образцов (Пк) оказывает существенное влияние на микротвердость сплавов. В общем случае, $H_{\mu}$ тем выше, чем выше оказывается плотность материала после осадки, особенно это влияние заметно для образцов сплава 1. При этом степень деформационного упрочнения бронзовых образцов влияет на величину микротвердости значительно более слабо, чем плотность, и в результате $H_{\mu}$ меньше у образцов, напряжение течения которых при прессовании было выше.

Данные табл. 1 позволяют также сделать интересное заключение относительно характера пластического течения материала сплавов при прессовании. Так, при примерно равной величине осадки пористость образцов оказывается тем выше, чем ниже была температура их прессования. Следовательно, сильное упрочнение и высокий предел текучести спеченной бронзы не способствуют однородному распределению деформации по объему осаживаемых образцов.

$$
-187-
$$


Таблица 1. Влияние температуры деформирования на остаточную пористость (П) и микротвердость $\left(\mathrm{H}_{\mu}\right)$ спеченного порошкового сплава $\mathrm{Cu}-15$ ат.\% $\mathrm{Al}$ (1) и $\mathrm{Cu}-24$ ат.\% $\mathrm{Al}$ (2)

Table 1. Effect of the deformation temperature on the residual porosity $(\mathrm{P})$ and microhardness $\left(\mathrm{H}_{\mu}\right)$ of the sintered powder alloy $\mathrm{Cu}-15$ at. \% $\mathrm{Al}(1)$ and $\mathrm{Cu}-24$ at. \% $\mathrm{Al}(2)$

\begin{tabular}{|c|c|c|c|}
\hline Состав & $T_{\text {деф}, ~}{ }^{\circ} \mathrm{C}$ & $\Pi_{k}, \%$ & $H_{\mu}$, MПа \\
\hline \multirow{4}{*}{1} & 20 & $5,9 \pm 2$ & $1300 \pm 50$ \\
\cline { 2 - 4 } & 250 & $9,0 \pm 1,5$ & $1233 \pm 61$ \\
\cline { 2 - 4 } & 370 & $11,9 \pm 3$ & $994 \pm 25$ \\
\cline { 2 - 4 } & 500 & $5,2 \pm 1,7$ & $1452 \pm 37$ \\
\cline { 2 - 4 } & 600 & $3,5 \pm 0,6$ & $1468 \pm 70$ \\
\hline \multirow{4}{*}{2} & 20 & $17,2 \pm 4$ & $1359 \pm 41$ \\
\cline { 2 - 4 } & 250 & $11,4 \pm 2$ & $2020 \pm 72$ \\
\cline { 2 - 4 } & 370 & $14,4 \pm 1,4$ & $1223 \pm 43$ \\
\cline { 2 - 4 } & 500 & $3,7 \pm 0,3$ & $2452 \pm 67$ \\
\hline
\end{tabular}

Повышенная концентрация алюминия и высокое напряжение течения материала вблизи больших исходных пор приводит к тому, что данные области не вовлекаются в пластическое течение образцов, а заключенные в них поры мало меняют свою конфигурацию. И только нагрев сплавов до $500{ }^{\circ} \mathrm{C}$ и выше способствует разупрочнению таких областей и вовлечению их в пластическое течение. В результате деформация исходных пор становится пропорциональной величине деформации всего образца.

\section{Выводы}

Таким образом, из представленных результатов следует, что осадку спеченных бронзовых образцов для их уплотнения и модификации структуры следует проводить при температуре не ниже $500{ }^{\circ} \mathrm{C}$. Однако ввиду возможного интенсивного окисления при нагреве спеченных пористых образцов из алюминиевой бронзы их пластическую обработку следует начинать при пониженных температурах до исчезновения открытой пористости, и только затем температура прессования может быть повышена.

В ходе высокотемпературной осадки происходит разрушение исходной дендритной или эвтектоидной структуры спеченной бронзы, она измельчается, что способствует увеличению прочности материала. Кроме того, при высокой температуре прессования пластическое течение принимает однородный характер, что помогает исчезновению крупных остаточных пор и уплотнению бронзовых образцов, повышению их микротвердости. Таким образом, появляется возможность применения спеченной бронзы в нагруженных узлах трения, где прежде преимущественно использовались литые бронзы.

Работа выполнена при финансовой поддержке гранта РФФИ №16-38-00200 мол_а. 


\section{Список литературы}

[1] Федорченко И.М., Андриевский Р.А. Основы порошковой металлургии, Киев, Изд-во AH УССР, 1963, 420 c. [Fedorchenko I.M., Andrievskii R.A., Fundamentals of Powder Metallurgy, Kiev: Publisher Academy of Sciences of the UkSSR, 1963 [in Russian]

[2] Сегал В.М., Резников В.И., Малышев В.Ф. Порошковая металлургия, 1979, 7, С. 6 [Segal V.M., Reznikov V.I., Malishev V.M., Powder metallurgy, 1979, 7, 7 [in Russian]

[3] Салтыков С.А. Стереометрическая металлография, М., Металлургия, 1970, 376 с. [Saltikov S.A. Stereometric metallography. Moscow: Metallurgy, 1970 [in Russian]

[4] Korosteleva E.N., Pribytkov G.A. and Gurskikh A.V. Bulk changes and structurization in solid-phase sintering of titanium-silicon powder mixtures. Powder Metallurgy and Metal Ceramics, 2009, 48(1-2), 8-12.

[5] Диаграммы состояния двойных металлических систем, под общей ред. Н.П. Лякишева, Т.1, М., Машиностроение, 1996. 996 с. [Liakishev N.P. Diagrams of binary metallic systems. Moscow: Mechanical Engineering, 1996, 996 p. [in Russian]

[6] Коростелева Е.Н., Русин Н.М. Гурских А. В. Изменение структуры спеченной алюминиевой бронзы после обработки методом интенсивной пластической деформации. Физическая мезомеханика, специальный выпуск, 2004, 7, $73-74$ [Korosteleva E. N., Rusin N.M., Gurskikh A. V. Changes in the structure of the sintered aluminum bronze after treatment by severe plastic deformation. Physical Mesomechanics, 2004, 7, 73-74 [in Russian] 